\title{
The use of Gamification in Knowledge Management Processes: A Systematic Literature Review
}

\author{
Marta Correia Sampaio ${ }^{1, *}$, Maria José Sousa ${ }^{2}$ and Andreia Dionísio ${ }^{3}$ \\ ${ }^{1}$ Universidade de Évora, Cefage, Portugal; ${ }^{2}$ ISCTE Instituto Universitário de Lisboa, Portugal; ${ }^{3}$ Universidade \\ de Évora, Cefage, Management Department, Evora, Portugal
}

\begin{abstract}
Purpose: The purpose of this article is to present a systematic literature review that synthesizes the investigations made into the use of Gamification in Knowledge Management processes in recent years, and a conceptual model for analysis of the Gamification of Knowledge Management Systems.

Theories: Since the last decade the Gamification - defined by the application of game design principles in a non-game context - as a management practice has become increasingly challenging for researchers. At the height of the Knowledge Age, in which we live today, knowledge and the organizational capacity to create, disseminate and retain it is one of the most important sources of competitive advantage for organizations. As employees' knowledge is critical for companies, it is essential to find effective mechanisms to encourage collaborators to share knowledge. In this field, gamification is a dynamic to be considered as an enabler of successful knowledge management systems.

Methodology: A systematic review of the literature was carried out, analyzing the scientific articles obtained through electronic databases, manual research and the cross-referencing of bibliographic references to identify and synthesize studies on the use of gamification in Knowledge Management processes in the period from 2015 to 2018.

Results: This study demonstrates that the use of gamification in knowledge management processes has a positive impact on employees' motivation and involvement with these systems, while promoting the creation, transfer and sharing of knowledge in the organization. A conceptual model for the gamification of knowledge management systems is proposed, intended to be a valid contribution to the operationalization of future studies on the link between gamification and knowledge management.
\end{abstract}

Keywords: Gamification, Knowledge management, Literature review.

\section{INTRODUCTION}

Gamification has captured the interest of researchers and the growing number of academic and non-academic articles (Hamari, Koivisto, \& Sarsa, 2014) on this subject demonstrates exactly this.

The term Gamification refers to the use of game design elements outside the game context (Deterding, Sebastian, Dixon, Khaled \& Nacke, 2011). This dynamic is often used to create applications or systems in organizations with the aim of encouraging specific behaviors or changing patterns of behavior. Gamification can be found in several domains, ranging from health to marketing, education, crowdsourcing or customer loyalty, and is also used in team motivation or productivity (Raftopoulos et al., 2015; Seaborn \& Fels, 2015).

With business competitiveness essentially based on knowledge (Sharif \& Zakaria, 2005; Martins, 2010), organizations with an intensive environment for the creation and sharing of knowledge gain a competitive advantage over their competitors.

Therefore, this paper seeks to show empirical evidence of the importance of gamification in

*Address correspondence to this author at the Universidade de Évora, Cefage, Portugal; E-mail: d38576@alunos.uevora.pt knowledge management processes, namely in creating and maintaining an organizational environment conducive to learning, skills development and knowledge generation.

A framework of the knowledge management and gamification concept has been developed, together with a systematic review of the literature to analyze how gamification is used in knowledge management processes, the impact of this use and the problems arising from it. This leads to proposing an analysis model that helps to identify to what extent gamification can have an impact as a dynamic facilitator of knowledge management

\section{KNOWLEDGE MANAGEMENT}

In recent years, with increasing globalization, the rapid development of information and communication technologies, the emergence of new, more flexible and horizontal forms of work and organization, there has been a change in the structure of economies. Knowledge has gained a major role in organizations and value creation is no longer based solely on tangible resources, to rely primarily on intangible resources.

Knowledge has become a pillar for organizations. Drucker (1994) states in his book "Post Capitalist Society," that the decisive 'production factor' is not 
capital, land or labor, (Polanyi, 1966; Nonaka \& Takeuchi, 1997; Davenport \& Prusak, 1998; Strauhs, 2003). According to Jorge and Faléco (2016: page 69), it is "one of the most valuable tools that organizations have today, coming from the intellectual capital of each collaborator", and organizational strategies must focus more and more on human capital, on their qualifications, skills and knowledge, since effective management of this resource will create value and achieve greater performance (Serrano \& Fialho, 2005).

Currently, knowledge management is developing and increasingly practiced in organizations, with companies recognizing the importance of managing their intangible assets. Brand development, stakeholder relationships, the organization's reputation and culture are seen as the major sustainable sources of business advantage (Chong, Holden, Wilhelmij \& Schmidt. 2000). In knowledge-intensive organizations, processing knowledge is critical to business success (Halawi, Aronson, \& McCarthy (2005) cit. Prahalad \& Hamel, 1990). For Drucker (1988), the ability to develop and raise the value of these intangible assets is a core competency for organizations.

There is a general consensus that knowledge management will represent the most important competitive advantage factor for organizations (Prahalad \& Hamel, 1990, Halawi et al., 2005, Quinn, 1992, Grant, 1996, Davenport \& Prusak, 1998; Sharkie, 2003; Spender, 2014).

At the heart of the movement's paradigm (António, 2015), the key to any organization's success is its ability to transform and evolve permanently, and the ability to rethink and question its activities, structures and systems regularly. Dominating new sources of value, the creative dimension of economic activity means abandoning routine and tradition and emphasizing novelty (innovation, originality, diversity). With knowledge being the most important strategic resource for business (Hadad, 2017, Shujahat, Sousa, Hussain, Nawaz, Wang \& Umer, 2017), companies should focus on designing real knowledge strategies to improve their competitiveness through a rational assessment of internal resources and the external competitive environment, also considering existing turbulence and uncertainties (Bolisani \& Bratianu, 2017).

\section{Models of Knowledge Management}

Organizational Knowledge Management implies the existence of processes for the creation, codification and application of knowledge in the organization, with management taking the necessary steps to create an open environment to embrace a knowledge management project, namely time, resources and employee motivation (Nonaka \& Takeuchi Hirotaka 1997, Leonard-Barton 1998, Probst 1998, Sveiby 1998, Davenport \& Prusak 1998).

Several models of organizational knowledge management have been presented by various authors over time, aiming to promote the dissemination of knowledge in organizations and presenting management practices and leadership to support this. Within the scope of our work, the post-2000 models, included in the Strategic Intention (Paradigm of Movement) phase, are added to the SECl Model (Nonaka \& Takeuchi, 1995), which is still one of the creation and dissemination of organizational knowledge (Mohajan, 2017). Table 1 compiles knowledge management models and their authors, the basic assumptions of each knowledge management model and the type of practice / organizational environment that the authors defend as essential for the creation and management of knowledge (Table 1):

\section{GAMIFICATION}

Games are an integral part of our society, where people appreciate the feeling of winning points, rewards and autonomy, overcoming challenges and obstacles, always with associated fun elements. Assuming this, the idea of gamification is to pass these sensations associated with games to the organizational context, allowing the company to collect valuable information about the behavior of customers, employees and activities at various points of contact, including applications used through the Internet, mobile devices and social networks.

Gamification, defined by Kapp (2012: page 11) as a "mechanism based on game dynamics, designed and thought with the intention of involving people, generating action, motivating, promoting learning and solving problems" is a recent organizational research theme Rinc, 2014). It is often necessary to apply the principles of play to the organizational environment when the intention is to increase employee involvement, which is why it seems pertinent to consider gamification as a strategic tool for knowledge.

According to Duarte (2016), individuals' social mutation has made organizational game dynamics a strategic tool for the processes of knowledge 
Table 1: Knowledge Management Models

\begin{tabular}{|c|c|c|c|}
\hline Author/year & KM Model & Assumptions of the KM Model & $\begin{array}{l}\text { Environment and practices } \\
\text { required to implement the KM } \\
\text { Model }\end{array}$ \\
\hline $\begin{array}{c}\text { Mohajan (2017) op cit } \\
\text { Stankosky \& Baldanza } \\
\text { (2001) }\end{array}$ & $\begin{array}{c}\text { Stankosky \& Baldanza } \\
\text { Model }\end{array}$ & $\begin{array}{c}\text { Managing knowledge is an engineering project } \\
\text { that has external influences at the political, social, } \\
\text { governmental and economic levels, and the } \\
\text { organization must rely on four essential pillars: } \\
\text { leadership, structure and organizational culture, } \\
\text { technology and learning. Technological } \\
\text { infrastructure should promote efficient and } \\
\text { effective capture of tacit and explicit knowledge }\end{array}$ & $\begin{array}{c}\text { Leadership; } \\
\text { Organizational structure and } \\
\text { culture; } \\
\text { Technology and learning; } \\
\text { Technological infrastructure } \\
\text { should promote efficiency and } \\
\text { capture tacit and explicit } \\
\text { knowledge }\end{array}$ \\
\hline \multirow[t]{2}{*}{ Hariharan, (2005) } & 360 Degree Model & $\begin{array}{l}\text { A Knowledge Management system is based on } \\
\text { six dimensions, with the central dimension of } \\
\text { business: for each business priority, this model } \\
\text { creates a knowledge repository that helps } \\
\text { specialists in the area to improve the performance } \\
\text { of this measure: a community of experts. What do } \\
\text { customers say, relevant internal knowledge } \\
\text { base? Relevant external knowledge base? } \\
\text { Replication of knowledge in business units }\end{array}$ & $\begin{array}{c}\text { Knowledge repository: } \\
\text { Community of experts; } \\
\text { Relevant internal knowledge } \\
\text { base; } \\
\text { Relevant external knowledge } \\
\text { base; } \\
\text { Replication of knowledge in } \\
\text { business units }\end{array}$ \\
\hline & $\begin{array}{l}\text { Model of Complex } \\
\text { Adaptive Systems }\end{array}$ & $\begin{array}{c}\text { A CAS is a way of thinking and analyzing things, } \\
\text { recognizing complexity, patterns and } \\
\text { interrelations rather than just focusing on causes } \\
\text { and effects. Many elements interact dynamically, } \\
\text { any element of the system can be affected by and } \\
\text { affect other systems. There are non-linear } \\
\text { interactions, that is, small changes can have } \\
\text { great effects }\end{array}$ & $\begin{array}{l}\text { Dynamic interaction; constant; } \\
\text { Collection of knowledge; } \\
\text { Replication and application of } \\
\text { knowledge; }\end{array}$ \\
\hline
\end{tabular}


(Table 1). Continued.

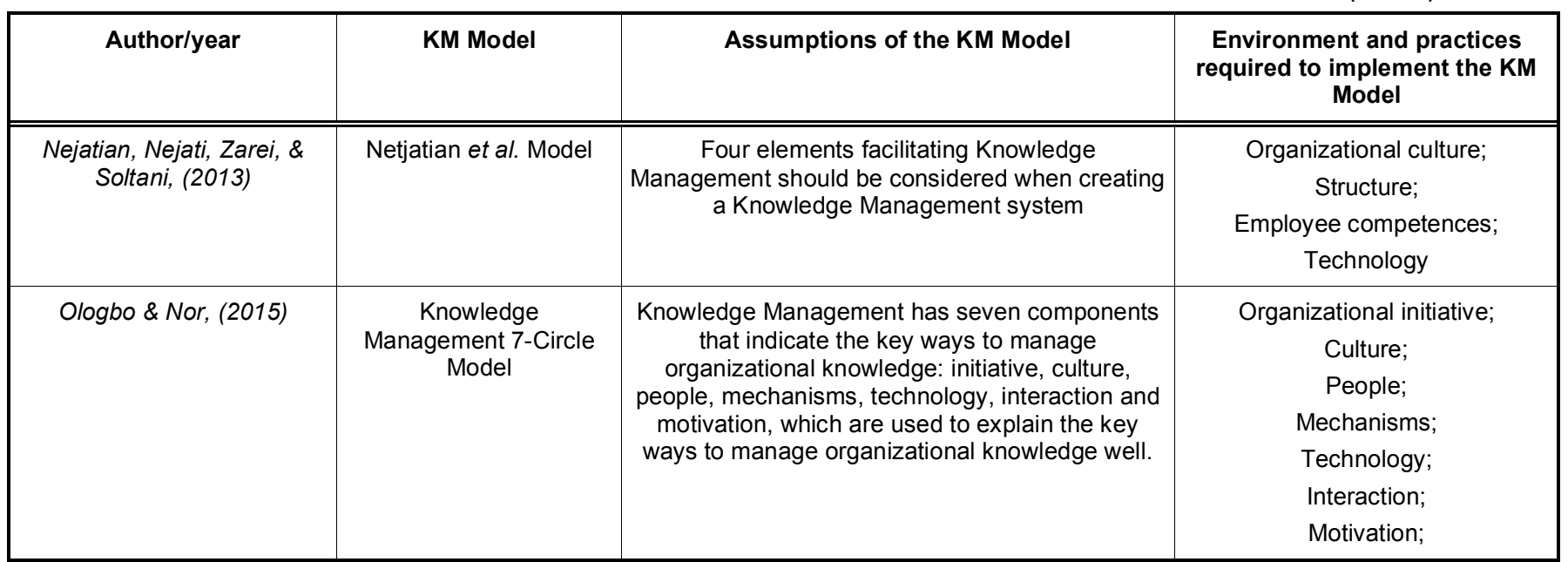

Source: Sampaio et al. (2019).

construction and management in the context of organizational intelligence. If individuals are directly affected by the environment, their preferences and motivations accompany them to their workplace, and the organization should explore those preferences in order to achieve organizational goals.

Kapp (2012) mentions six situations and activities in which gamification can be used as a strategy: Encourage; Analyze Progress through content; Motivate actions; Influence Behaviors; Lead to innovation; and Skills development and Knowledge acquisition.

According to Duriník (2015), the added value gamification can represent for companies through points, badges, challenges, rankings and other elements of the games provided on a platform where they can compete, increase their self-esteem and help them meet the higher needs of the Maslow pyramid, lies in greater employee engagement that will generate more input for the organization, which can be instrumental in pursuing innovation.

The gamification concept refers to an emerging organizational practice, defined by the use of game mechanics and design to measure, influence and reward target user behaviors. Gamification uses the essence of game features - goals, rules, fun elements, feedback, rewards and promotions - to solve day-today business problems, running these game mechanics, in a non-game context, as a catalyst to make technology more engaging, influencing the user's behavior and the methods of social interaction in organizations (Maan, 2013).
Because it is a recent area of research, it is important to analyze the evolution of the concept in the literature (Table 2).

According to recent studies, most organizations use gamification to motivate sharing, increase stakeholder engagement and explore relationships with the external context, leveraging the company's social platforms and networking practice. It is used to introduce new ways of thinking, designing and implementing solutions aligning the objectives of the game with the desired results for the organization, increase the visibility of the organization's processes and incorporate real experiences of interaction with colleagues, clients and suppliers, and assist in the identification and retention of talents (Maan, 2013).

\section{Gamification Categories}

Werbach and Hunter (2012) propose a framework to evaluate the three main areas in which gamification can be applied and add value in these same activities (Figure 1):

External gamification is intended to involve companies with their market, that is, with their current and potential customers. These practices are, as a rule, driven by marketing objectives. In this case, gamification may be a way to improve relations between companies and their clients (Werbach \& Hunter, 2012).

Internal gamification, also known as organizational gamification (Werbach \& Hunter, 2012), aims to involve employees and create and / or modify the database associated with the company, in order to make it more efficient for its users (Čudanov, Parlić , Sofronijević, 
Table 2: Definition of Gamification

\begin{tabular}{|c|c|}
\hline Definition & Source \\
\hline The use of game design elements in non game contexts " & Deterding et al. (2011) \\
\hline $\begin{array}{c}\text { "The phenomenon of using digital games to solve social problems and engage the public is known as } \\
\text { Gamification." }\end{array}$ & McGonigal, J. (2011) \\
\hline "Gamification leads to workers becoming more involved." & Clark, T. (2011) \\
\hline "The use of game mechanics to improve business processes, customer experiences or profits." & Lovel, L. (2011) \\
\hline $\begin{array}{c}\text { "The integration of mechanics, style, thinking and / or game design techniques to engage people in } \\
\text { solving a problem." }\end{array}$ & Zichermann \& Cunningham (2011) \\
\hline $\begin{array}{l}\text { "A process of improving a service with incentives to experience gaming in an organizational context in } \\
\text { order to support the creation of global value for the user." }\end{array}$ & Huotari \& Hamari (2012) \\
\hline $\begin{array}{c}\text { "The use of game dynamics that aim at engagement and education of the audience, as well as } \\
\text { problem solving. }\end{array}$ & Kapp (2012) \\
\hline "The application of typical elements of games in other areas of activity." & The Oxford Dictionary (2013) \\
\hline "It's a process of doing more game-like activities." & Werbach (2014) \\
\hline $\begin{array}{c}\text { "The use of game mechanics and design experiences to engage digitally and motivate people to } \\
\text { achieve their goals." }\end{array}$ & Gartner, op cit Paharia (2014). \\
\hline $\begin{array}{c}\text { "A successful gamification strategy is directly related to a correct perception of the surroundings } \\
\text { where the user is inserted, and their identification of their extrinsic fears and limitations, provided by } \\
\text { the external environment, and intrinsic, interconnected with self-motivation." }\end{array}$ & Chou (2016) \\
\hline
\end{tabular}

Source: authors' elaboration.

2014). Companies use gamification to improve organizational productivity (Werbach \& Hunter, 2012), with a view to stimulating innovation, improving employee relationships (Rauch, 2013) and achieving positive results through the employees themselves (Werbach \& Hunter, 2012).

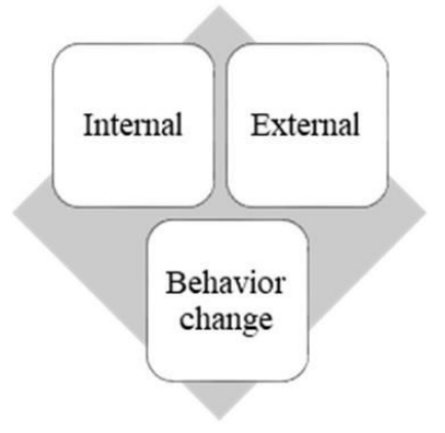

Figure 1: Gamification Application Areas. Source: Adapted from Werbach and Hunter (2012).

In the area of behavior change, gamification may help create new habits that are more beneficial to the population, which may include, for example, encouraging users to choose healthier living habits or even encouraging savings and economies (Werbach \& Hunter, 2012).

Reflecting on these areas of gamification action, they are seen to fit into many of the management practices the authors point out as facilitators of the knowledge management system, which reinforces our conviction that gamification can be considered an important tool for the implementation of a knowledge management model.

\section{Organizational Gamification}

Maan (2013) mentions four major areas that are benefited when using gamification from the internal point of view, as seen in Figure 2.

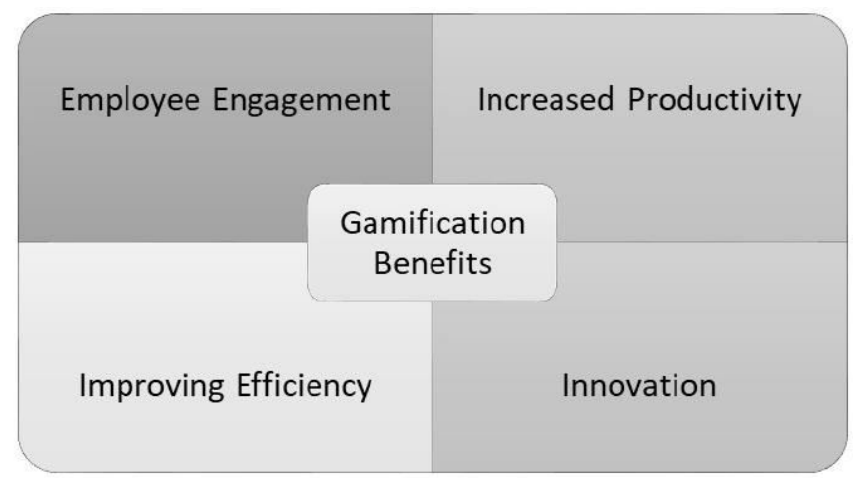

Figure 2: Benefits of Organizational Gamification. Source: Maan, 2013.

Many companies use gamification to encourage their employees to participate in, and contribute to existing communication and collaboration platforms in 
organizations, increasing the degree of employee engagement. (Mann, 2013; Suh, Cheung, Ahuja, \& Wagner 2017; Petelczyc, Capezio, Wang, Restubog, \& Aquino, 2018). Others use gamification data flows as Key Performance Indicators (KPIs), using the monitoring of employee interactions and contributions as performance measurement metrics, which ultimately influences efficiency and performance, and the organization's overall productivity (Maan, 2013; Robson, Plangger, Kietzmann, McCarthy \& Pitt, 2015).

Improved efficiency appears as a collateral advantage of collaborators' use of gamification (Maan, 2013, Francisco, Jorge, \& Sutton, 2016; Vinichenko, Melnichuk, Kirillov, Makushkin, \& Melnichuk.., 2016). The mechanics associated with this practice allow employees to check the time spent in their function's daily activities. Something as simple as responding to emails can be time-consuming and if employees constantly observe the time spent on this type of activity, which is not essential for their goals, they end up becoming more efficient and save time that can be allocated to other functions.

The last benefit of gamification mentioned is innovation. Authors such as Mann (2013) or Roth, Schneckenberg and Tsai (2015) argue that companies, in this transformational phase of daily business, are increasingly aware of the importance of using social technology platforms to encourage employees' contributions that help create value for the business, giving creative ideas for new services and innovation in processes and products directed to the market. Several organizations are using the mechanics of gamification to encourage these initiatives, encouraging all stakeholders to participate in organizational platforms that allow the incubation, sharing and execution of ideas from all areas of the organization, which generate rewards and motivation for participants who have a positive impact on the business

Gamification can be a useful tool to obtain customers' commitment and motivation, and activate their behavior and loyalty (Deterding et al., 2011, Zichermann \& Cunningham, 2011, Kumar \& Raghavendran, 2015, Petelczyc et al., 2018)

According to Rauch (2013), in a business context, the use of gamification increases the commitment and motivation of employees and corporate clients. According to the same source, this technique can help companies respond to various business needs, such as the following:
Stimulation of innovation. Gamification is an important tool to stimulate employees' contribution in terms of new ideas, for example, business or products, solutions to internal problems that improve efficiency and therefore innovation is enhanced in the organization;

ii) Motivation and retention of employees. In a context where talent retention and employee motivation is a constant challenge in organizations' everyday life, gamification emerges as a motivating practice for employees which can have an impact on their intention to stay with the company;

iii) Obtaining the commitment of internal and external communities. In most organizations, the external and internal environment has an impact on the day-to-day business and strategy, and one of the great challenges is to achieve commitment both internally and externally, for example, among suppliers and customers. Gamification is often a powerful tool here, with the points cards many companies use to retain customers being a clear example of this;

iv) Increasing commitment, adopting new ideas, learning and loyalty. With the evolution of work relations and collaborators' mentalities, it is increasingly difficult to get them involved with the organization and show their loyalty and commitment. Using game dynamics, involvement with the game turns out to be also fruitful in terms of commitment to colleagues and to the organization itself, as well as the learning, adoption and application in the course of its function of stimulating new ideas;

v) Improved efficiency and quality of service. When the organizational environment is uncertain, there are more contributions from stakeholders and greater participation in the business. Improved efficiency and quality of service is a collateral impact of using gamification;

vi) Support in maintaining the company's competitive position. All the points mentioned so far mean improved business efficiency in terms of innovation, learning and commitment in line with the strategic objectives of the business. This will be a competitive advantage that could make a difference in the organization's market position; 
vii) Knowledge of customer expectations. As already mentioned, gamification can guarantee external communities' involvement with the organization and the contribution of key customers. Customers committed to the company provide information about their expectations for products, services, promotional campaigns or distribution sites, which is essential for organizations to innovate and meet their needs;

viii) Reducing time and costs. Most organizations are looking for operational efficiency - lower costs, higher productivity among others, and here, gamification is an interesting tool since, as already seen, it has a significant impact on innovation and employees' motivation and efficiency;

ix) Increasing the return on investment. Currently, organizations choose to make investments in procedures that guarantee them return. According to the above, gamification is an organizational practice to bank on, since it demonstrates a return for the companies that use it; and

x) Obtaining greater profits. Organizations that achieve a competitive advantage over their competitors will be in a better position to be more profitable.

\section{Characteristics and Key Elements of Gamification}

There is still no unanimously accepted definition of game design elements (Dicheva, Dichev, Agre, \& Angelova, 2015), but three stand out: the game dynamics, the game mechanics and the components of the game (Werbach \& Hunter, 2012). While the first relate to the general characteristics of the game, as regards the players' emerging behavior as they participate in the experience which is determined by the mechanics of the game (as defined by their designers), the second are the concrete elements used in the game that lead the players to carry out a certain action in a given context. For Robson et al., (2015, page 415), the mechanics applied to the dynamics of the game are "decisions that the game designers make to specify the objectives, the rules, scenario, context, types of interaction and the limits of the situation to be gamified. " Finally, the components are the most visible and structural elements of the game: awarding points, reward mechanisms, type of participation (Robson et al., 2015).
For Ralph and Monu (2015, page 8), game mechanics should be understood as: "Algorithms, rules, objects, actions and other components of the game that are manipulated by game designers to create challenges for players."

In the typical architecture of any gamification initiative, the game mechanics include some common key elements such as rewards and incentives, badges, leaderboards, virtual links and creativity (Maan, 2013, Burke, 2014, Lister, 2015).

Rewards and incentives encourage desired behaviors among employees. Emblems demonstrate different levels of achievement when certain milestones are reached, classification tables help organizational actors to know where they are compared to their peers, involving a spirit of competition, creativity, strategic tactics, applied knowledge or time, in order to create a ranking among players, which will act as a motivating element for all players involved. As for virtual connections, the use of mobile devices and constant access to the Internet allows instant access to social networks, anytime, anywhere. When the game is designed to be played through these channels, it is easier to increase the level of involvement with the game and the number of interactions with other players. Finally, Levels and Reputation appear, the first representing the player's degree of involvement in the business's entire value chain, this being the basis to define players' rewards. As for reputation, this is the community's trust in each player and provides the system and stakeholders with feedback on the relevance of the questions asked and answers given by each player (Maan, 2013).

\section{METHODOLOGY}

A systematic review was conducted according to Hemingway and Brereton (2009) to answer three research questions guiding this study in order to obtain an unbiased synthesis and interpretation of the results of studies on the subject (Gough, Oliver \& Thomas, 2017). A systematic review is defined by Tranfield, Denyer, \& Smart (2003: page 209) as a replicable, scientific and transparent process that seeks to minimize the bias that exhaustive bibliographic research of published and unpublished studies may originate. The same authors suggest that the systematic review process provides a more reliable basis for research, because it is based on comprehensive understanding of what is known about a subject and is therefore relevant to researchers as a 
way of summarizing what has repeatedly arisen within the scope of investigations, making it easier to access that knowledge not only for researchers but for the wider community.

The purpose of this type of review is to respond to a clearly formulated question using systematic and explicit methods to critically identify, select and evaluate relevant research, and collect and analyze data on the subject being reviewed (Clarke \& Oxman, 2000; Oakley, 2012). For Bryman (2012), the main steps to be followed in a systematic review should be: i) definition of the objective and the scope of the review, ii) the search for studies relevant to the scope and purpose of the review, iii) and iv) analysis of each study that will result in a synthesis of the results of these studies.

Considering that the problem underlying the present study concerns understanding the use of gamification in knowledge management processes, it is possible to define as the objective of the study, according to Waddington, White, Snilstveit, Hombrados, Vojtkova, Davies \& Bhavsar (2012), a precise description of "What is going to be done" to answer the research question. To obtain additional detailed knowledge about the use of game dynamics in knowledge management processes, we believe that a systematic literature review is appropriate, using as research questions:

1) Research Question One: What are the research purposes, methodologies and results of studies on the use of gamification in knowledge management?

2) Research Question Two: What are the main barriers to implementation of Knowledge Management Gamification identified in the surveys?

3) Research Question Three: In what contexts has research been carried out and what is the geographical distribution of studies?

\section{Research Strategy}

The methodological process used in this research was based on PRISMA (Preferred Reporting Items for Systematic Reviews and MetaAnalyses), which aims to ensure that systematic reviews (SR) and metaanalyses are performed in a complete and clear way (Liberati, Altman, Tetzlaff, Mulrow, Gøtzsche, loannidis, Clarke, Devereaux, Kleijnen, \& Moher, 2009)
Research and literature reviews provide the "raw material" for a systematic review (SR). The development of a comprehensive research strategy can be considered a specific competence, and therefore, this stage was considered as something to develop in a precise and effective way (Waddington et al., 2012). The research should cover literature sources in three key areas: research in electronic databases, manual search and cross-referencing (Waddington et al., 2012). This literature research was formally carried out in mid-December 2018, in the main scientific databases, using the b-on multidisciplinary database.

\section{Study Selection}

The population of this study consisted of all the scientific articles obtained through research in electronic databases, manual search and cross reference bibliographies, and that met the eligibility criteria previously defined by the authors. The eligibility criteria are intended to specify the characteristics of the studies to be included in the sample (for example, through the PICOS - Participants, Interventions, Comparators, Outcomes and Study design approach) and the characteristics of the articles (publication date, languages considered). These were: (i) Date of publication - articles published between January 2015 and December 2018; ii) Language - articles published in English; iii) Publication - articles published in peerreviewed journals and scientific journals; iv) Study population - articles that focus on the use of gamification as a management practice or tool, associated with knowledge management in organizations. Authors refer to these themes using different nomenclatures, and the most common nomenclature was analyzed in the publications (Table 3 ).

Table 3: Most Common Nomenclature in the Key Words of the Subject under Study

\begin{tabular}{|c|c|}
\hline Knowledge Management & Gamification \\
\hline \hline Knowledge Management; & Gamification; \\
\hline Knowledge Transfer; & Serious Games. \\
\hline Sharing Knowledge. & \\
\hline
\end{tabular}

Source: Authors' elaboration.

From this, all possible combinations originating in six key words guiding our research were validated: a) "Knowledge Management and Gamification", b) "Knowledge Management and Serious Games"; c) "Transfer of Knowledge and Gamification"; d) "Transfer of Knowledge and Serious Games", e) Sharing 
Table 4: Systematic Review: Inclusion / Exclusion Criteria

\begin{tabular}{|c|c|}
\hline Inclusion Criteria & Exclusion Criteria \\
\hline \hline Application of Gamification to Knowledge Management Processes & $\begin{array}{c}\text { Papers that did not consider the topic of research from the } \\
\text { Gamification perspective applied to Management }\end{array}$ \\
\hline Original Research Paper & Use of social networks and Wikis \\
\hline Peer Reviewed Paper & Paper full text access \\
\hline & Investigations of applied technology in the creation of serious games \\
\hline
\end{tabular}

Source: Sampaio et al. (2019).

Knowledge and Gamification "and f) Knowledge Sharing and Serious Games", which resulted in 395 articles listed.

\section{Inclusion / Exclusion Criteria}

This systematic review used the inclusion / exclusion criteria detailed in Table 4. All studies should have all inclusion criteria and none of the exclusion criteria to be considered in this systematic review.

The 375 articles were reviewed in light of the inclusion and exclusion criteria, resulting in the removal of 66 articles because they were duplicated and the exclusion of 219 articles because they did not have the criterion of the use of Gamification for Management / Knowledge Transfer. The remaining 90 articles were reviewed and 55 of these eliminated due to exclusion criteria such as addressing the use of simulators, health or other aspects, and being technology-based studies on the technology used in creating serious games. The number of articles in line with all the criteria in Table 4 was 35, with the research and literature review process appearing in Figure 3.

\section{Analysis Framework}

Six elements were chosen to carry out the analysis based on research questions: 1) purpose of the study, 2) methodology used, 3) results, 4) research domain, 5) study context, 6) study countries. In this review, each research element was individually coded to ensure that the context and initial meaning of the data were preserved as indicated by Sandelowski, Voils, Leeman and Crandell (2012). In order to analyze the purpose of the studies, we considered the keywords as well as important words. This was an iterative and inductive process, a constant comparison being made between the data presented as the purpose of the study and the categories of purpose codified initially so that at the end all purposes fit into one of the categories.

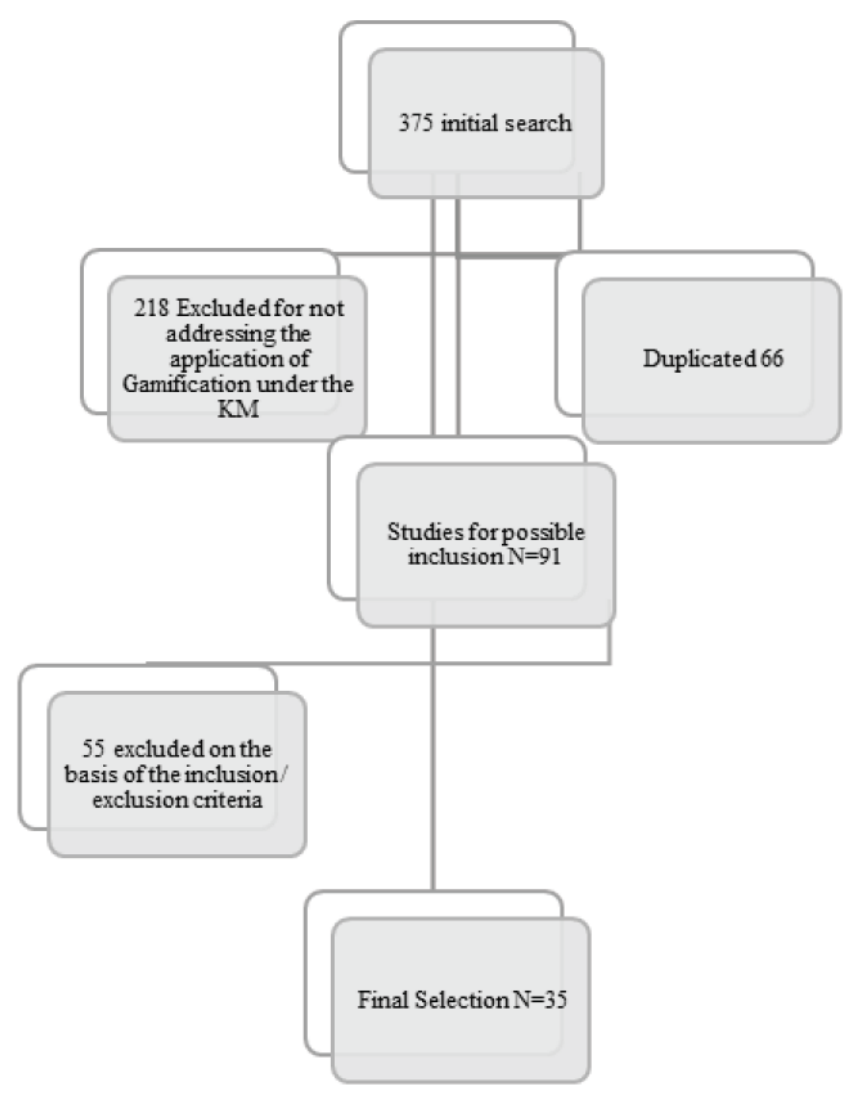

Figure 3: Diagram of the Research Process and Literature Review. Source Sampaio et al. (2019).

With regard to the research methodology, it was necessary to create a code, which according to Bryman (2012) is essential for content analysis, helping to establish a structure of ideas on each theme under analysis, defining how to treat the constant information in the articles and helping to classify the topics of interest for the study. This coding was based on the meta-data of the articles, and the levels were created using the terminology used by the researchers, called "in vivo coding" (Saldana, 2014). In terms of the results of studies, coding considered the impact of gamification use as positive, negative or neutral. The studies coded as positive were those that demonstrated positive results in knowledge management systems using gamification. In cases where the use of gamification did 
not show any change in the knowledge management system, the studies were classified as neutral. Negative are those where no result was detected from gamification being used in the knowledge management systems. Regarding the study contexts, coding considered where the studies were made: "organizations", and within these, the sector of activity, which generated several levels; "Universities", or "not applicable" when the studies were about literature reviews.

Regarding the origins of studies, due to the geographical dispersion, coding was by continent, the majority of work originating in the American continent, closely followed by studies done in Europe and Asia.

\section{RESULTS AND DISCUSSION}

Research Question One: What are the research purposes, methodologies and results of studies on Knowledge Management and Gamification?

\section{Research Purposes}

When analyzing the 35 articles, it was possible to code five categories regarding the purposes of the studies (Table 5):

Investigation into the impact of gamification on the sharing and transfer of knowledge was the most frequent study purpose, with $22 \%$ of studies being coded in this way. This impact was measured in several ways, for example, Swacha (2015) and LI (2018) evaluated this impact on the motivation for knowledge transfer, Salman, et al. (2016) the use of gamification regarding knowledge transfer and organizational learning practices and Suh et al. (2017) dealt with the characteristics of knowledge sharing strategies based on the perspective of dynamic cooperative play. Interestingly, most of the studies focus on the impact of gamification as a tool for knowledge transfer and this impact has been studied in several ways, which provides a more robust basis for understanding how gamification can support knowledge sharing and transfer.

Four purposes of study follow closely, with frequencies of $17 \%$ in each category. "The use of Gamification in the processes of Knowledge Management", was analyzed by several authors such as Allal-Chérif and Makhlouf (2016), Francisco et al. (2016), Ahmed and Sutton (2017), who in the light of different perspectives analyzed how gamification can be used to manage knowledge. Gamification's impact on employees' involvement in the knowledge management process is another of the most frequent purposes of study, in terms of collaborators' specific perception (Kumar \& Raghavendran, 2015; Klasen, 2016) Gamification increases employees' contribution of knowledge (Suh \& Wagner, 2017) and in the work by Petelczyc et al. (2018) increases the motivation of new generations of employees towards the organizational learning and knowledge sharing that emerges from gamification. Jorge and Sutton (2017) looked at the mechanisms that stimulate gambling, since it is possible to analyze the reasons for employees adhering to gamification and playing in a serious context. Suh and Wagner (2017) investigated why employees play at work, while Hamari and Keronen (2017) analyzed the concept of "Funification" and how this feeling encourages employees' participation in the

Table 5: Purpose Categories of the Studies

\begin{tabular}{|c|c|c|}
\hline & Category & Description \\
\hline \hline 1 & Gamification as Management Practice & $\begin{array}{c}\text { Studies in this category evaluate the impact of the use of gamification } \\
\text { as a management practice }\end{array}$ \\
\hline 3 & Gamification and employee involvement in the Knowledge \\
Management System & $\begin{array}{c}\text { Studies in this category address the ways in which gamification can be } \\
\text { applied to knowledge management }\end{array}$ & $\begin{array}{c}\text { Studies in this category evaluate how the use of gamification has an } \\
\text { impact on employees' involvement with the knowledge management } \\
\text { system }\end{array}$ \\
\hline 4 & The stages of Knowledge Management and Gamification & $\begin{array}{c}\text { In this category, studies analyze the impact of the use of gamification } \\
\text { on the acquisition and creation of knowledge and its sharing and } \\
\text { transfer }\end{array}$ \\
\hline 5 & Employees and the game & $\begin{array}{c}\text { Studies in this category involve evaluation of users' perceptions of the } \\
\text { game, the mechanisms used in gamification to encourage gaming and } \\
\text { the forms of motivation that can be used in the gamification of } \\
\text { knowledge management systems. }\end{array}$ \\
\hline
\end{tabular}

Source: Sampaio et al. (2019). 
game. Last but not least, studies of employees' motivation for the game appear, from several perspectives. Suh et al. (2018) analyze the aesthetic experience and its role in motivation. Hamari, Hassan and Dias (2018) analyze the relation between players' individual goals and their willingness to play. LI (2018) analyzes the cooperative dynamics emerging from gamification and how this has an impact on the motivation of organizational actors.

Still in the domain of the stages of the knowledge management process and gamification, but concerning the creation and acquisition of knowledge, fewer studies were detected when compared to knowledge transfer, $11 \%$ vs $22 \%$. However, the work by Suorsa (2015) is important, analyzing the relationship between knowledge creation and play, as well as Vallat, Bayart and Bertezene (2016), who discuss the impact of gamification on organizational learning.

Regarding users' perceptions of the game, $11.4 \%$ of studies were included in this domain, with perceptions of gamification in the work context (Kumar \& Raghavendran, 2015; Wozniak, 2017) being analyzed, as well as factors that may affect employees' acceptance of gamification (Klasen, 2016).

Finally, with the smallest number of articles, only about $5 \%$, studies on gamification as a management practice emerge. The work of Robson et al. (2015) is very important in analysis of the principles of gamification and how this can be seen as a management practice, being complemented by the investigation by Vinichenko et al. (2016) into the ways of applying gamification to business.

\section{Research Methods}

As shown in Table 6, most of the studies analyzed were exploratory, addressing the existing literature on the state of the art of the relationship between gamification and knowledge management, which is in line with Singhsomransukh and Heo (2017)): "Although there are already some studies on Gamification, organizational learning and knowledge sharing, very few are empirical and link these concepts." Empirical studies are, in most cases, investigations that resort to case studies where from application of a game associated with knowledge management, interviews, focus groups, questionnaires or even direct observation are used to evaluate the impact of gamification on the domain to be investigated in light of the purpose of the research. Analyzing these data, we can see the recent stage of the investigation into the connection between these contexts. Several different methods are adopted to investigate the use of gamification in knowledge management, which provides very interesting data to help the academic community (Petelczyc et al., 2018). In order to improve knowledge about the use of gamification as a tool for knowledge management systems, future research needs more qualitative and quantitative studies (Petelczyc et al., 2018).

Table 6: Research Methods of the Studies

\begin{tabular}{|c|c|}
\hline Methods & Number of studies \\
\hline \hline Literature Review & 14 \\
\hline Survey & 10 \\
\hline Interview & 2 \\
\hline Focus Group & 1 \\
\hline Direct Observation & 1 \\
\hline Game Theory & 1 \\
\hline Quantitative & 8 \\
\hline
\end{tabular}

Source: Sampaio et al. (2019).

\section{Search Results}

In this review, 35 articles were analyzed. Of the 35 studies, 19 focused on the impact of gamification on knowledge management, both on the knowledge management system itself and on the creation, acquisition, sharing and transfer of knowledge. The results of these 19 studies were analyzed and coded as positive, negative or neutral. Fourteen (74\%) of these studies report positive results, that is, gamification improved the creation, acquisition, sharing and transfer of knowledge, four of these studies $(21 \%)$ refer to neutral results and only one refers to some negative results (Figure 4). Many variables can impact on the creation and sharing of knowledge through gamification: individual, organizational, the task performed, emotional factors and others (Robson et al., 2015, Hamitel \& Keronen, 2017 and Petelczyc et al., 2018). In order to better understand the impact of gamification on knowledge management processes, research is needed to provide a more in-depth look at these variables and how they contribute to explaining the results.

Research Question Two: What are the Main Barriers to the Implementation of Knowledge Management Gamification Identified in the Surveys?

Of the analyzed articles, only three address barriers to the use of gamification as an organizational practice. 


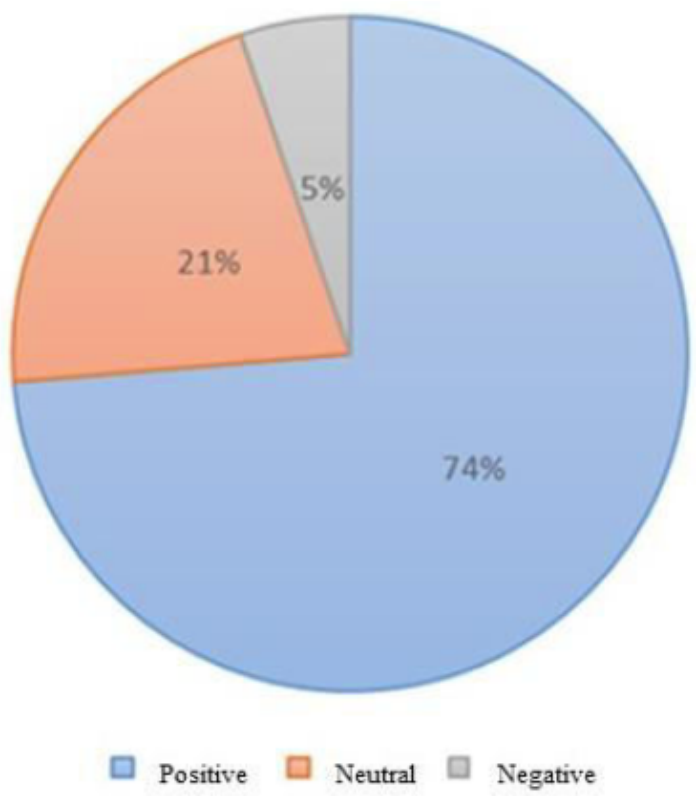

Figure 4: Distribution of Search Results. Source: Sampaio et al. (2019).

The barriers identified can be classified into three individual groups of infrastructure or game design and ethics, as follows:

a) Individuals - barriers related to the users of the game and how they face it. These barriers include employees' involvement being only temporary, the learning that comes from gamification not being incorporated into daily activities (Francisco et al., 2016), users' personality having an impact on their reaction to gamification in the workplace or loss of interest in the rewards offered (Cardador et al., 2017).

b) Infrastructure / game design - determined by the organization, in terms of its organizational structure and also by the game's creator and the mechanisms used in its design. The studies refer, for example, to the lack of time available for employees to play (Francisco et al., 2016), there is no real-time feedback (Cardador, et al., 2017), simplification of reality and little meaning of the game for users (Rapp \& Tirassa, 2017) or the rewards scheme is poorly designed (Swacha, 2015);

c) Deontological - barriers associated with use of the game as an organizational practice concerning, for example, the invasion of players' privacy, the existence of manipulation or even ethical problems that may emerge (Cardador et al., 2017).
Research Question Three: In what Contexts has Research been Carried Out and what is the Geographical Distribution of Studies?

Most of the empirical studies (19) were carried out in an organizational context $(73 \%)$ mainly in the services sector - banking (2), consultancy firms (2), but also in retail companies (1) and in SMEs (1) or companies in the nuclear sector (1). The remaining studies were carried out in universities (5) with university students.

Regarding the origins of studies, the majority come from the United States, followed by France and India and the United Kingdom, as seen in Figure $\mathbf{5}$.

\section{Proposal of a Conceptual Model for the Gamification of Knowledge Management Systems}

According to Gloet and Terziovski (2004), knowledge management is the formalization of experience and how to access this knowledge and proficiency, which produces new skills. The systematic review of the literature revealed the use of gamification as a tool of knowledge management. There are strong indicators of a positive impact when using this recent organizational practice. Therefore, it seemed important to us, based on the studies analyzed, to create a conceptual model to allow in-depth study of the link between gamification and knowledge management (Figure 6):

As we have already seen, implementation of a knowledge management system implies that the organization intends to promote the creation of knowledge and apply this knowledge in the business itself in order to obtain a competitive advantage. Analysis of the literature revealed which factors can facilitate the implementation of a knowledge management system. The first relevant factor is leadership. It is the organization's leadership that is responsible for taking measures to implement gamification (Ologbo \& Nor, 2015; Stankosky \& Baldanza, cited by Mohajan, 2017) and ensuring that all the conditions are met for this implementation to take place for the system to work according to its objectives.

Four main pillars of a knowledge management system were identified: i) organizational culture, ii) organizational structure, iii) people in the organization, and iv) information technology. Regarding organizational culture, this is the existence of a collaborative environment, where there is trust and a 


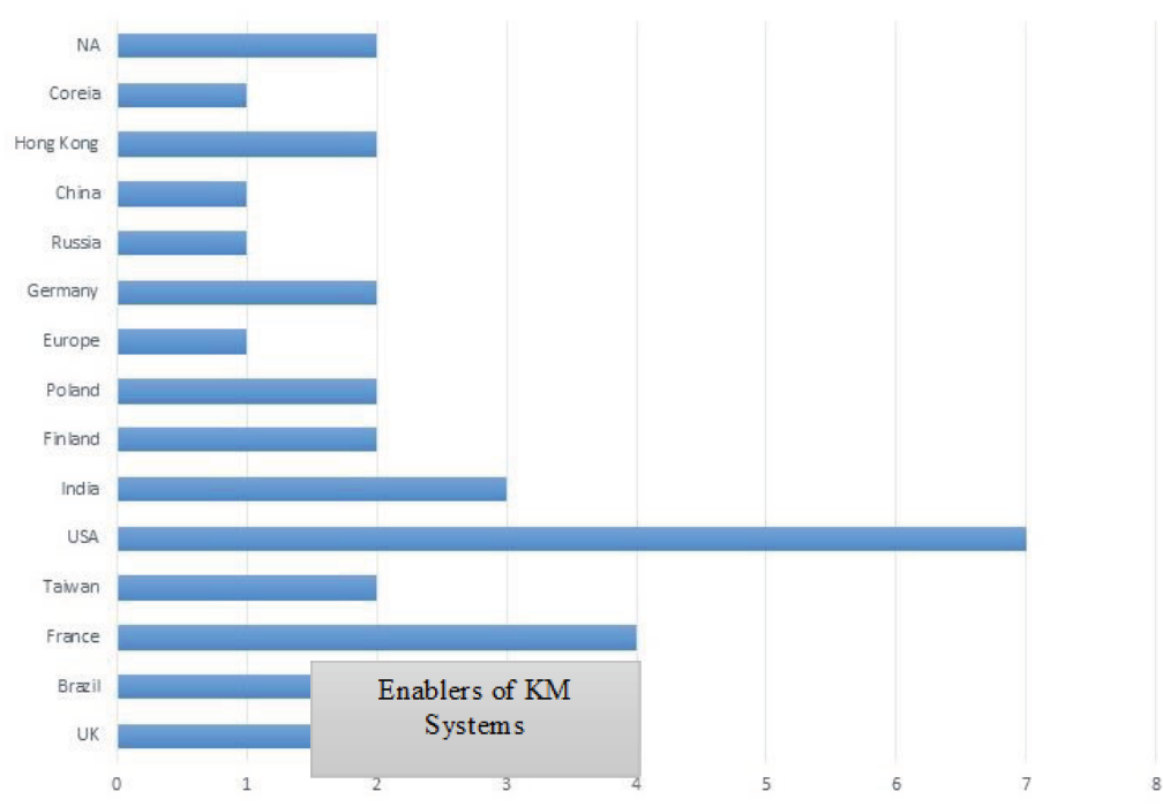

Figure 5: Distribution of studies by country.

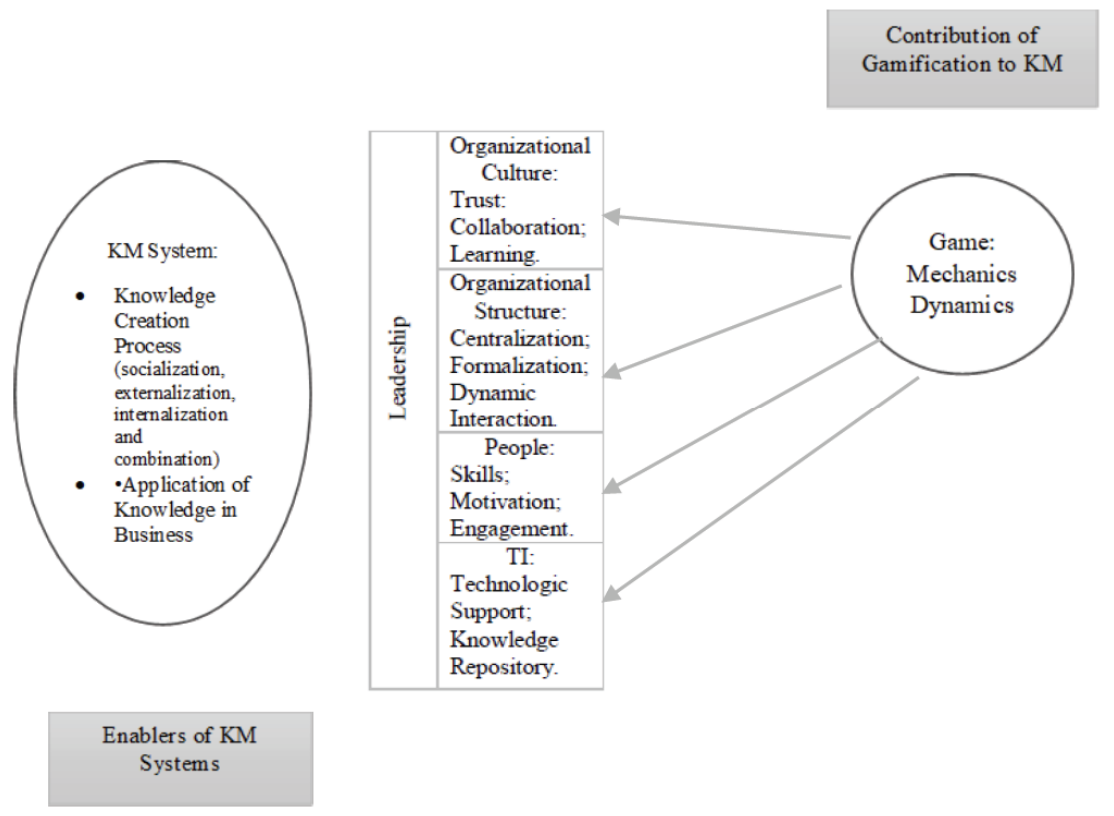

Figure 6:

focus on organizational learning, essential for the success of a knowledge management system (Choo, 1996; Neotian et al., 2013, Ologbo \& Nor, 2015, Stankosky \& Baldanza, cited by Mohajan, 2017). The organizational structure must be designed in order to feed this organizational environment. There must be a formalized and centralized structure that helps to collect data and information and that owns and accesses this knowledge, but also allows for the dynamic interaction between the organization's members, regardless of their area or sector of activity
(Nonaka \& Takeuchi, 1995), Krogh \& Roos, 1995, Stacey, 1996, Wenger \& Synder 2000, Kakabadse et al., Ologbo \& Nor, 2015, Ologbo \& Nor, 2015, Stankosky \& Baldanza, cited by Mohajan, 2017). As for employees, it is very important for the success of any knowledge management system that people have competencies in specific technical areas, but at the same time have a sense of the potential impact of their specific tasks while being motivated to make their contribution to the knowledge management system. Only then will it be possible to share knowledge, 
disseminate it through the organization and empower it with a view to creating more and more up-to-date knowledge that can be applied in the organization (Noraka \& Takeuchi, 1995; Wenger \& Synder, 2000; Nejatian, et al., 2013; Ologbo \& Nor, 2015). Last but not least, for the implementation of a knowledge management system, information technology emerges (Kakabadse et al., 2003; Nejatian, et al., 2013, Ologbo \& Nor, 2015, Stankosky \& Baldanza, cited by Mohajan, 2017). Technological support is currently essential for knowledge management (Sousa et al., 2018) and through this support it is easier to create repositories of knowledge in the organization to serve as an organizational memory available for consultation and use by employees, in the environment of dynamic interaction and collaboration that we have already talked about.

Gamification as a management practice can be a tool to support the implementation of knowledge management systems, that is, it can be an external facilitator. Based on the dynamics and mechanics applied when creating the serious game to be implemented in the organization, the positive effects of the items described above could be enhanced (Francisco et al., 2016; Suh \& Wagner, 2017; Hamari \& Keronen, 2017; LI, 2018) as well as knowledge sharing (Swacha, 2015;LI, 2018; Petelczyc et al., 2018), increased competition for the attainment of the organization's objectives (Werbach \& Hunter, 2012, Maan, 2013, Robson et al., 2015 ), implementation of an enterprise strategy (Werbach \& Hunter, 2012; Rauch, 2013), employee development (Salman et al., 2016; Vallat et al., 2016, Sousa \& Rocha, 2018), and establishing intra and extra company partnerships to achieve objectives (Rauch, 2013) Designing performance indicators (KPIs) associated with the gamification process, involving cooperation and collaboration between employees and their contributions to levels of knowledge, can also be an effective way of collecting and storing the knowledge that can be directed from the game directly to the knowledge repositories deemed appropriate by the organization.

\section{LIMITATIONS}

The objective of this work was to systematically create a conceptual model to analyze how gamification, as an organizational practice, has an impact on knowledge management systems. This systematic review is limited to a period of time, and despite including the most recent studies, this selection may not be a representation of all published work on the subject. In addition, these articles only represent peerreviewed work written in English, not reflecting articles written in other languages.

Concerning the proposed conceptual model, this needs to be developed, namely in terms of the barriers to gamification in knowledge management systems, the creation of a measuring instrument that can analyze the impact of gaming on each factor facilitating knowledge management, together with a case study of application of the model in a real context to be able to evaluate it.

\section{CONCLUSION}

Through a systematic literature review, this study aimed to present the main research carried out on the use of game dynamics - gamification - in knowledge management systems, looking at the purposes of the studies, the methodology used, the results, the contexts investigated, the barriers encountered and the geographical distribution of the investigations. A total of 35 articles were analyzed. We found that the most common theme in the analyzed articles is gamification in the sharing and transfer of knowledge, and recurrent themes are the impact of gamification on employees' involvement in the knowledge management process and study of the mechanisms that encourage the game. Analysis of these articles showed that gamification has positive impacts on knowledge management systems, namely in creating dynamic interaction and cooperation, motivating employees to transfer knowledge, organizational learning, empowering employees' involvement and commitment to the knowledge management system. It was also demonstrated that one of the determining factors for success in knowledge management systems is the game's design and the dynamics and mechanics incorporated therein, the analyzed studies demonstrating that if the game is built in line with the collaborators' expectations, this is a determinant of adhesion to gamification. As for the barriers to gamification, there were three main categories: those deriving from the design of the game itself and the organizational infrastructure, those deriving from employees' individual characteristics and, lastly, deontological ones that have to do with employees' privacy and rights.

Of the papers analyzed, the great majority of articles correspond to a literature review, with very little empirical work in this area of research being done in 
organizational and university contexts, underlining the shortage of work focused on the barriers presented to gamification in organizations.

We can affirm that in fact few articles deal with the use of gamification in knowledge management, with this review showing that investigation on this theme is a new and growing trend, with all publications identified being from the last ten years, so there is still a lot of ground to be explored in this area.

Based on this study, it can be argued that the most pressing need in this area is to gather evidence of the practical application of gamification as a tool of a knowledge management system and its impact. Studies should be carried out in more sectors of activity where gamification is applied and in a larger number of companies simultaneously, in order to allow better data analysis and thus more reliable results. Moving away from university-only research and extrapolating studies into the business environment will help to improve understanding of the link between gamification and knowledge management processes.

\section{IMPLICATIONS OF THE STUDY}

Therefore, this article presents a proposal for a model of analysis created from the bibliographic review and the studies analyzed, which we consider to be an important contribution to future research. It can identify to what extent gamification can have impact as a facilitating dynamic of knowledge management, allowing researchers aware of this theme a deeper and more focused analysis of the areas involved in knowledge management where gamification has effectively has impact.

A data collection instrument can be created for application in a real context, allowing data to be collected and analyzed to provide evidence of the effective impact of gamification on knowledge management processes.

\section{FUTURE INVESTIGATIONS}

Based on the proposed conceptual model, future research should seek to create a metric that allows evaluation, in a real context, of the effective impact of using gamification on knowledge management processes, especially in organizational context. From application of the model presented in this study in future studies, it can be reformulated and rationalized in order to be as close as possible to a model that effectively reflects how gamification as an organizational practice can have an impact on knowledge management systems.

\section{ACKNOWLEDGEMENT}

The authors are pleased to acknowledge financial support from Fundação para a Ciência e a Tecnologia (grant UID/ECO/04007/2019).

\section{REFERENCES}

Ahmed, Allam, and Michael J.D. Sutton. 2017. "Gamification, Serious Games, Simulations, and Immersive Learning Environments in Knowledge Management Initiatives." World Journal of Science, Technology and Sustainable Development 14 (2/3): 78-83. https://doi.org/10.1108/WJSTSD-02-2017-0005

Allal-Chérif, Oihab, and Mohamed Makhlouf. 2016. "Using Serious Games to Manage Knowledge: The SECl Mode Perspective." Journal of Business Research 69 (5): 1539-43. https://doi.org/10.1016/j.jbusres.2015.10.013

Antonio, Nelson. 2015. Estratégia Organizacional: Do Posicionamento Ao Movimento. [Organizational Strategy: From Positioning to Movement] $2^{a}$ Edição. Lisboa: Edições Sílabo.

Bolisani, Ettore, and Constantin Bratianu. 2018. "The Emergence of Knowledge Management." In Emergent Knowledge Strategies: Strategic Thinking in Knowledge Management, 23-47.

https://doi.org/10.1007/978-3-319-60657-6 2

Bryman, Alan. 2012. Social Research Methods. 4th Editio. New York: Oxford University Press.

Burke, Biran. 2014. Gamify: How Gamification Motivates People to Do Extraordinary Things. Gartner, Inc.

Cardador, M. Teresa, Gregory B. Northcraft, and Jordan Whicker 2017. "A Theory of Work Gamification: Something Old, Something New, Something Borrowed, Something Cool?" Human Resource Management Review 27 (2): 353-65. https://doi.org/10.1016/j.hrmr.2016.09.014

Chong Chee W., Tony Holden, Paul Wilhelmij, and Ruth A. Schmidt. 2000. "Where Does Knowledge Management Add Value?" Journal of Intellectual Capital 1 (4): 366-83. https://doi.org/10.1108/14691930010359261

Choo, C W. 1996. "The Knowing Organization: How Organizations Use Information to Construct Meaning, Create Knowledge and Make Decisions." International Journal of Information Management 16 (5): 329-40. https://doi.org/10.1007/BF01072060

Chou, Yu-Kai. 2016. "Actionable Gamification: Beyond Points, Badges, and Leaderboards." In CEUR Workshop Proceedings. https://doi.org/10.1017/CBO9781107415324.004

Clarke, M., and A. Oxman. 2000. Cochrane Reviewers' Handbook Version 4.1. Oxford: The Cochrane Collaboration.

Čudanov M, Parlić D, Sofronijević A (2014). "Proposed framework for gamifying information retrieval: Case of DART-European research theses portal" ACM International Conference Proceeding Series: pp. 185-190 Published by Association for Computing Machinery. https://doi.org/10.1145/2669711.2669898

Davenport, T.H. \& Prusak, L. 1998. Working Knowledge: How Organizations Manage What They Know. Knowledge Creation Diffusion Utilization. https://doi.org/10.1109/EMR.2003.1267012

Deterding, Sebastian, Dan Dixon, Rilla Khaled, and Lennart Nacke. 2011. "From Game Design Elements to Gamefulness: 
Defining 'Gamification."' Proceedings of the 2011 Annual Conference Extended Abstracts on Human Factors in Computing Systems - CHI EA '11. https://doi.org/10.1145/1979742.1979575

Dicheva, D, C. Dichev, G. Agre, G. Angelova. 2015. "Gamification in education: a systematic mapping study", Educ. Technol. Soc. 18 (3):75-88

Drucker, Peter. 1994. Post-Capitalist Society. UK: Taylor \& Francis Ltd.

Drucker, Peter F. 1988. "Management and the World's Work." Harvard Business Review 66 (5): 65-76.

Duuriník, Michal. 2015. "Gamification in Knowledge Management Systems." Central European Journal of Management 1 (2). https://doi.org/10.5817/CEJM2014-2-3

Gloet, Marianne, and Milé Terziovski. 2004. "Exploring the Relationship between Knowledge Management Practices and Innovation Performance." Journal of Manufacturing Technology Management. https://doi.org/10.1108/17410380410540390

Gough, David, Sandy Oliver, and James Thomas. 2017. "Introducing Systematic Reviews." In An Introduction to Systematic Reviews. https://doi.org/10.1186/2046-4053-1-28

Grant, Robert M. 1996. "Toward a Knowledge Based Theory of Frim." Strategic Management Journal 17: 109-22. https://doi.org/10.1002/smj.4250171110

Hadad, Shahrazad. 2017. "Knowledge Economy: Characteristics and Dimensions." Management Dynamics in the Knowledge Economy 5 (2): 203-25. https://doi.org/10.25019/MDKE/5.2.03

Halawi, L, J Aronson, and R McCarthy. 2005. "Resource-Based View of Knowledge Management for Competitive Advantage." Knowledge Management 3 (2): 75-86.

Hamari, Juho, Lobna Hassan, and Antonio Dias. 2018. "Gamification, Quantified-Self or Social Networking? Matching Users' Goals with Motivational Technology." User Modeling and UserAdapted Interaction 28 (1): 35-74. https://doi.org/10.1007/s11257-018-9200-2

Hamari, Juho, and Lauri Keronen. 2017. "Why Do People Play Games? A Meta-Analysis." International Journal of Information Management 37 (3): 125-41. https://doi.org/10.1016/j.ijinfomgt.2017.01.006

Hamari, Juho, Jonna Koivisto, and Harri Sarsa. 2014. "Does Gamification Work? - A Literature Review of Empirical Studies on Gamification." In Proceedings of the Annual Hawaii International Conference on System Sciences. https://doi.org/10.1109/HICSS.2014.377

Hariharan, Arun. 2005. "360 Degree of Knowledge Management." Journal of Knowledge Management Practice 6 (May): 1-8. ISSN 1705-9232

Hemingway, P., and N. Brereton. 2009. "What Is a Systematic Review?" Hayward Medical Communications 2: 1-8.

Jorge, Carlos F.B., and Michael J D Sutton. 2016. "Games Como Estratégia Na Construção e Gestão Do Conhecimento no Contexto Da Inteligência Organizacional." [Games how strategy in building and knowledge management in the organizational intelligence context]. Perspectivas Em Gestão \& Conhecimento - Numero Especial 6: 103-18. http://periodicos.ufpb.br/ojs2/index.php/pgc.

Jorge, Carlos Francisco Bitencourt, and Lyvia Luppi Faléco. 2016. "A Aplicação Da Gestão Do Conhecimento Como Estratégia de Competitividade Organizacional." [The Application of Knowledge Management as an Organizational Competitiveness Strategy]. Brazilian Journal of Information Studies: Research Trends 3: 69-75. ISSN 1981-1640.

Jorge, Carlos Francisco Bitencourt, and Michael J.D. Sutton. 2017. "Funification 2.0." World Journal of Science, Technology and Sustainable Development 14 (2/3): 84-110. https://doi.org/10.1108/WJSTSD-11-2016-0060
Kakabadse, Nada K., Andrew Kakabadse, and Alexander Kouzmin. 2003. "Reviewing the Knowledge Management Literature: Towards a Taxonomy." Journal of Knowledge Management. https://doi.org/10.1108/13673270310492967

Kapp, Karl M. 2012. The Gamification of Learning and Instruction: Game-Based Methods and Strategies for Training and Education. Pfeiffer. https://doi.org/10.1145/2207270.2211316

Klasen, James. 2016. "Employess' Experiences and Perceptions of Work Gamification."

Krogh, Georg Von, and Johan Roos. 1995. Organizational Epistemology. New York: St Martin`s Press. https://doi.org/10.1002/smj.4250151005

Kumar, Hari, and Satish Raghavendran. 2015. "Gamification, the Finer Art: Fostering Creativity and Employee Engagement." Journal of Business Strategy 36 (6): 3-12. https://doi.org/10.1108/JBS-10-2014-0119

Leonard-Barton, Dorothy. 1998. Nascentes Do Saber: Criando e Sustentando as Fontes de Inovação. Rio de Janeiro: Fundação Getulio Vargas.

LI, Kun. 2018. "Multi-Context Research on Strategy Characteristics of Knowledge Sharing in Organization Based on Dynamic Cooperative Game Perspective." Journal of Knowledge Management 22 (4): 850-66. https://doi.org/10.1108/JKM-09-2017-0420

Liberati, Alessandro, Douglas G. Altman, Jennifer Tetzlaff, Cynthia Mulrow, Peter C. Gøtzsche, John P.A. Ioannidis, Mike Clarke, P. J. Devereaux, Jos Kleijnen, and David Moher. 2009. "The PRISMA Statement for Reporting Systematic Reviews and Meta-Analyses of Studies That Evaluate Health Care Interventions: Explanation and Elaboration." In Journal of Clinical Epidemiology. https://doi.org/10.1016/j.jclinepi.2009.06.006

Lister, Meaghan. 2015. "Gamification: The Effect on Student Motivation and Performance at the Post-Secondary Level." https://doi.org/10.2458/azu itet_v3i2_Lister

Maan, Jitendra. 2013. "Social Business Transformation Through Gamification." International Journal of Managing Information Technology (IJMIT) 5 (3): 9-16. https://doi.org/10.5121/ijmit.2013.5302

Martins, José Moleiro. 2010. Gestão Do Conhecimento - Criação e Transferência de Conhecimento. [Knowledge Management Knowledge Creation and Transfer].1 ${ }^{a}$ Edição. Lisboa: Edições Sílabo.

Mettler, Tobias, and R. Pinto. 2015. "Serious Games as a Means for Scientific Knowledge Transfer - A Case from Engineering Management Education." IEEE Transactions on Engineering Management 62 (2): 256-65. https://doi.org/10.1109/TEM.2015.2413494

Mohajan, Haradhan. 2017. "The Impact of Knowledge Management Models for the Development of Organizations." Journal of Environmental Treatment Techniques 20175 (1): 12-33. https://mpra.ub.uni-muenchen.de/83089/1/MPRA_paper_ 83089.pdf.

Nejatian, Majid, Mehran Nejati, Mohammad Hossein Zarei, and Somaye Soltani. 2013. "Critical Enablers for Knowledge Creation Process: Synthesizing the Literature." Global Business \& Management Research 5 (2/3): 105-19. http://ezproxy.staffs.ac.uk/login?url=http://search.ebscohost.c om/login. aspx?direct=true\&db=bth\&AN=91508676\&site=eho st-live.

Nonaka, Ikujiro, and Hirotaka Takeuchi. 1995. The KnowledgeCreating Company: How Japanese Companies Create the Dynamics of Innovation. New York: Oxford University Press.

Ologbo, Andrew C., and Khalil Nor. 2015. "The 7-Circle Model: A Practical and Coherent KM Model for Managing Organizational Knowledge." Mediterranean Journal of Social Sciences 6 (4): 120-28. https://doi.org/10.5901/mjss.2015.v6n4s1p120 
Petelczyc, Claire Aislinn, Alessandra Capezio, Lu Wang, Simon Lloyd D. Restubog, and Karl Aquino. 2018. "Play at Work: An Integrative Review and Agenda for Future Research." Journal of Management 44 (1): 161-90.

https://doi.org/10.1177/0149206317731519

Polanyi, M. 1966. The Tacit Dimension. London: Routledge \& Legam Paul.

Prahalad, Coimbatore K, and Gary Hamel. 1990. "The Core Competencies of the Corporation." Harvard Business Review 68 (3): 79-91.

https://doi.org/10.1016/j.ydbio.2010.09.018

Probst, Gilbert. 1998. "Practical Knowledge Management: A Model That Works." Prism-Cambridge Massachusetts-, 17-30. https://www.researchgate.net/publication/271508998 Practic al_Knowledge_Management_-_A_Model_That_Works.

Raftopoulos, Marigo, Steffen Walz, and Stefan Greuter. 2015. "How Enterprises Play: Towards a Taxonomy for Enterprise Gamification." DiGRA 2015: Diversity of Play: Games Cultures - Identities.

Ralph, Paul, and Kafui Monu. 2015. "Toward a Unified Theory of Digital Games." The Computer Games Journal 4 (1-2): 81100.

https://doi.org/10.1007/s40869-015-0007-7

Rapp, Amon, and Maurizio Tirassa. 2017. "Know Thyself: A Theory of the Self for Personal Informatics." Human-Computer Interaction 32 (5-6): 335-80. https://doi.org/10.1080/07370024.2017.1285704

Rauch, Marta. 2013. "Best Practices for Using Enterprise Gamification to Engage Employees and Customers." In Lecture Notes in Human Computer Science, 276-83. https://doi.org/10.1007/978-3-642-39262-7_31

Rinc, Sergej. 2014. "Integrating Gamification with Knowledge Management." Management, Knowledge and Learning, International Conference, 997-1003.

Robson, Karen, Kirk Plangger, Jan H Kietzmann, lan McCarthy, and Leyland Pitt. 2015. "Is It All a Game? Understanding the Principles of Gamification." Business Horizons 58 (July): 411-20.

https://doi.org/10.1016/j.bushor.2015.03.006

Roth, Steffen, Dirk Schneckenberg, and Chia Wen Tsai. 2015. "The Ludic Drive as Innovation Driver: Introduction to the Gamification of Innovation." Creativity and Innovation Management. https://doi.org/10.1111/caim.12124

Saldaña, Johnny. 2014. The Coding Manual for Qualitative Researchers. Sage. https://doi.org/10.1007/s13398-014-0173-7.2

Salman, Munir, Jana Becker, Michael Fuchs, Dominic Heutelbeck, and Matthias Hemmje. 2016. "Enhancing Knowledge Management and Transfer in an Applied Gaming Ecosystem." In Proceedings of the European Conference on Knowledge Management, ECKM, 2016-Janua:786-95.

Sandelowski, Margarete, Corrine I. Voils, Jennifer Leeman, and Jamie L. Crandell. 2012. "Mapping the Mixed Methods-Mixed Research Synthesis Terrain." Journal of Mixed Methods Research 6 (4): 317-31.

https://doi.org/10.1177/1558689811427913

Seaborn, Katie, and Deborah I. Fels. 2015. "Gamification in Theory and Action: A Survey." International Journal of Human Computer Studies 74: 14-31. https://doi.org/10.1016/j.ijhcs.2014.09.006

Serrano, António, and Cândido J. Falé Fialho. 2005. Gestão Do Conhecimento - O Novo Paradigma Das Organizações. [Knowledge Management - The New Paradigm of Organizations]. $2^{\mathrm{a}}$ Edição. Lisboa: FCA - Editora de Informática.

Sharif, MNA, and NH Zakaria. 2005. "Facilitating Knowledge Sharing Through Lessons Learned System." Journal of Knowledge Management Practice 12 (March 2005): 117-24.
Sharkie, Rob. 2003. "Knowledge Creation and Its Place in the Development of Sustainable Competitive Advantage." Journal of Knowledge Management 7 (1): 20-31. https://doi.org/10.1108/13673270310463590

Singhsomransukh, Shivnetra, and Dongcheol Heo. 2017. "Gamification of Knowledge Sharing Practices: A Proposed Conceptual Framework for Organizational Learning." In Proceedings of the International Conference on Intellectual Capital, Knowledge Management \& Organizational Learning, 232-35.

http://search.ebscohost.com/login.aspx?direct=true \&db=edb \&AN=126894534\&site=eds-live.

Sousa, M. J., \& Rocha, A. (2018). Leadership styles and skills developed through gamebased learning. Journal of Business Research. https://doi.org/10.1016/j.jbusres.2018.01.057

Sousa, M. J., Carmo, M., Goncalves, A. C., Cruz, R., \& Martins, J. M. (2018). Creating knowledge and entrepreneurial capacity for $\mathrm{HE}$ students with digital education methodologies: Differences in the perceptions of students and entrepreneurs. Journal of Business Research. https://doi.org/10.1016/j.jbusres.2018.02.005

Spender, J.-C. 2014. "Making Knowledge the Basis of a Dynamic Theory of the Firm." Strategic Management Journal 17 (S2): 45-62. https://doi.org/10.1002/smj.4250171106

Stacey, Ralph D. 1996. Complexity and Creativity in Organizations. San Francisco, CA: Berrett-Koehler Publishers.

Strauhs, Faimara do Rocio. 2003. "Gestão Do Conhecimento Em Laboratório Acadêmico: Proposição de Metodologia." [Knowledge Management in Academic Laboratory: Methodology Proposition]. Universidade Federal de Santa Catarina. http://repositorio.ufsc.br/xmlui/handle/123456789/ 85440

Shujahat, M., Sousa, M. J., Hussain, S., Nawaz, F., Wang, M., \& Umer, M. (2017). Translating the impact of knowledge management processes into knowledge-based innovation: The neglected and mediating role of knowledge-worker productivity. Journal of Business Research. https://doi.org/10.1016/j.jbusres.2017.11.001

Suh, Ayoung, Christy M.K. Cheung, Manju Ahuja, and Christian Wagner. 2017. "Gamification in the Workplace: The Central Role of the Aesthetic Experience." Journal of Management Information Systems 34 (1): 268-305. https://doi.org/10.1080/07421222.2017.1297642

Suh, Ayoung, and Christian Wagner. 2017. "How Gamification of an Enterprise Collaboration System Increases Knowledge Contribution: An Affordance Approach." Journal of Knowledge Management 21 (2): 416-31. https://doi.org/10.1108/JKM-10-2016-0429

Suorsa, Anna Reetta. 2015. "Knowledge Creation and Play - A Phenomenological Approach." Journal of Documentation 71 (3): $503-25$ https://doi.org/10.1108/JD-11-2013-0152

Sveiby, K.E. 1998. "Measuring Intangibles and Intellectual Capital: An Emerging First Standard." http://www.sveiby.com.au/ EmergingStandard.htm

Swacha, Jakub. 2015. "Gamification in Knowledge Management Motivating for Knowledge Sharing." Polish Journal of Management Studies, Czestochowa Technical University, Department of Management, vol. 12(2), pages 150-160. December. https://www.scopus.com/inward/record.uri?eid=2s2.0-84953233433\&partner|D $=40 \& \mathrm{md} 5=e 57 \mathrm{~d} 34$ eefa82 $\mathrm{d}$ 3951 aee68c86dc66a25

Tranfield, David, David Denyer, and Palminder Smart. 2003. "Towards a Methodology for Developing Evidence-Informed Management Knowledge by Means of Systematic Review." British Journal of Management. https://doi.org/10.1111/1467-8551.00375 
Vallat, David, Caroline Bayart, and Sandra Bertezene. 2016. "Serious Games in Favour of Knowledge Management and DoubleLoop Learning?" Knowledge Management Research and Practice 14 (4): 470-77. https://doi.org/10.1057/kmrp.2015.29

Vinichenko, Mikhail V., Alexander V. Melnichuk, Andrei V. Kirillov, Sergey A. Makushkin, and Yulyia A. Melnichuk. 2016. "Modern Views on the Gamification of Business." Journal of Internet Banking and Commerce 21 (S3). https://doi.org/10.5539/ies.v8n5p179

Waddington, Hugh, Howard White, Birte Snilstveit, Jorge Garcia Hombrados, Martina Vojtkova, Philip Davies and Ami Bhavsar. 2012. "How to Do a Good Systematic Review of Effects in International Development: A Tool Kit." Journal of Development Effectiveness. https://doi.org/10.1080/19439342.2012.711765

Wen Chong, Chee, Tony Holden, Paul Wilhelmij, and Ruth A. Schmidt. 2000. "Where Does Knowledge Management Add Value?" Journal of Intellectual Capital 1 (4): 366-83. https://doi.org/10.1108/14691930010359261
Wenger, Etienne C, and WIlliam M Synder. 2000. "Communities of Practice: The Organizational Frontier." Harvard Business Review. https://doi.org/10.1177/0170840603024003909

Werbach, Kevin. 2014. "(Re)Defining Gamification: A Process Approach." In Lecture Notes in Computer Science (Including Subseries Lecture Notes in Artificial Intelligence and Lecture Notes in Bioinformatics), 8462 LNCS:266-72. https://doi.org/10.1007/978-3-319-07127-5 23

Wozniak Jacek. 2017. "Some Factors Hindering Acceptance of Three Gamification Solutions in Motivation Systems, in Small and Medium Enterprises." Management Dynamics in the Knowledge Economy 5 (4): 663-80. https://doi.org/10.25019/MDKE/5.4.11

Zichermann, G., and C. Cunningham. 2011. Gamification By Design Implementing Game Mechanics in Web and Mobile Apps. Gabriel Z. https://doi.org/10.1017/CBO9781107415324.004

DOI: https://doi.org/10.6000/1929-7092.2019.08.150

(c) 2019 Sampaio et al.; Licensee Lifescience Global.

This is an open access article licensed under the terms of the Creative Commons Attribution Non-Commercial License (http://creativecommons.org/licenses/by-nc/3.0/) which permits unrestricted, non-commercial use, distribution and reproduction in any medium, provided the work is properly cited. 